\title{
Transit Coordination in the U.S.: A Survey of Current Practice
}

\author{
Charles Rivasplata, Ph.D., San Jose State University \\ Hiroyuki Iseki, Ph.D., University of Maryland, College Park \\ Adam Smith, San Jose State University
}

\begin{abstract}
As cities expand and travel patterns become more complex, transit passengers are becoming increasingly dependent on multiple systems to satisfy their daily travel needs. To facilitate seamless travel, comprehensive service planning, design, and operation are essential. In some cases, regional entities have integrated routes, timetables, and ticketing based on a common set of planning, investment, and marketing principles. The authors administered a nationwide survey of transit operators to explore the following areas of integration: fare policy/media, service scheduling, information coordination, facility and vehicle coordination, and interagency agreements. According to survey results, the nature and extent of integration varied by size of region and type of integration. Respondents identified challenges to coordination, including financial and political commitment. Furthermore, for integration to be successful, regional and local transport entities must work together to ensure that service providers participate in coordinative strategies, balancing the interests and needs of passengers, operators, and residents.
\end{abstract}




\section{Introduction}

In today's world, many people require traveling long distances across multiple cities and towns to reach dispersed locations in order to conduct their various economic and social activities. The provision of transit service that accommodates seamless travel across transit systems in the region is ideal for transit users. In turn, this seamless travel across the region requires appropriate coordination and integration among transit agencies. Over the past few decades, there has been an increasing level of interest in improving the coordination of transit services among many cities and regions around the globe (Tyson 1990; Stokes 1994; White 2002).

The importance of regional coordination and integration has been well recognized by researchers and practitioners (Iseki and Taylor 2009; Rivasplata 2006; Miller et al. 2005; Meyer et al. 2005; Pucher and Kurth 1989). According to NEA, regional coordination/integration is defined as:

The organization process through which elements of the passenger transport system (network and infrastructure, tariffs and ticketing, information and marketing etc) are, across modes and operators, brought into closer and more efficient interaction, resulting in an overall positive enhancement to the overall state and quality of services linked to the individual travel components (NEA Transport 2003, 17).

Transit coordination features the comprehensive planning of services within an urban market for the purposes of facilitating seamless, multi-operator journeys. It entails the organization of modes and services into a system of operational features in terms of routes, frequencies, timetables, fares, and ticketing based on a common set of planning, marketing, and development principles (White 2002; Rivasplata 2006). Nevertheless, there have been relatively few attempts to comprehensively explore transit coordination from the perspective of the transit agency. While numerous studies have explored government and agency perspectives on transit coordination in other countries (Pucher and Kurth 1989; Stokes 1994; NEA Transport 2003), in the U.S., most work on transit coordination has been limited to larger metropolitan areas (MTC 2006) where many of the successful regional strategies have been developed.

The purpose of this study is to identify some of the salient features of transit coordination in the U.S. based on a nationwide survey of transit agencies. This on-line survey asked directors and planners at transit agencies across the nation to answer questions associated with major regional coordination issues for transit service in the following categories: (1) fare coordination, (2) service schedule coordination, 
(3) information coordination, (4) facilities/vehicle coordination, and (5) joint agreements.

The survey was part of a larger study that examined the effects of transit service contracting and the level of regional coordination in the New Orleans Metropolitan Area (Iseki et al. 2011). While the larger study focused on documenting transit service management and operation for improvements of services within individual transit systems as well as regional coordination in relation to privatization, this survey provided valuable information on the present status of transit coordination in the U.S. Based on the analysis of survey data, a number of inferences can be made concerning the impact of specific factors on regional integration in the United States.

In general, the survey questions sought to discern levels of coordination in the U.S., identifying the constraints to inter-operator collaboration as well as the opportunities offered for system improvements. The survey took a unique approach, exploring coordination from the viewpoint of transit operators, as opposed to a regional entity or transit passenger.

\section{Transit Coordination: Background}

Regional coordination and integration are essential for transit passengers who depend on more than one transit system for travel (Chisholm 1989; Cook, Lawrie, and Henry 2003; Miller et al. 2005; Pucher and Kurth 1989; NEA Transport 2003). Regional transit systems that are not well-coordinated can impose burdens on transit users, discourage transferring among multiple transit agencies, and decrease ridership. Some of the burdens that riders may face in an uncoordinated transit system are unpredictable travel times, long transfer times, and increased fare payments (Miller et al. 2005).

By coordinating services, some regions have been successful in reducing those burdens, thereby increasing ridership and customer service. The coordination of routes, schedules, and fares can promote the use of transit, especially in large cities where multiple operators provide bus and rail services and, in some cases, more than 10 percent of journeys involve a transfer (White 2002). Past studies have acknowledged that system integration can enhance mobility and access, improving the level of connectivity between systems and prompting transit as a viable mode of transportation for a wider range of trip purposes (Nash 1988; Tyson 1990; Simpson 1994; Stokes 1994; Hensher and Brewer 2001). 
While operators often attempt to serve a variety of origins and destinations, it is costly for them to provide direct service between all points, making some interchange inevitable (LTP 1997; White 2002). Passengers transfer when there is either no direct service or when transferring offers a faster alternative (TfL 2001). Transit coordination can effectively deliver more direct service by facilitating vital service connections at strategic locations. For transit to be a viable alternative, experts argue that operators must ensure security and reliability as well as reduce in-vehicle travel and transfer times, provide transfer information, and enhance throughticketing (Rivasplata 2000; TfL 2001; White 2002).

Where transit systems are integrated in a seamless network of services, commuters spend less time traveling and not only save time and money but also contribute less to urban congestion and pollution. While time-savings is of primary interest to middle- and high-income urban residents, cost savings is critical to the survival of low-income communities, as a higher percentage of their wages is spent on transport (Nash 1988; Wardman 2001). By attracting a higher proportion of travelers to transit, system coordination can help manage transportation demand and reduce traffic congestion and vehicle emissions. Transit can be coordinated so that passengers pay only once, network routing and vehicle headways facilitate transfers, and interchange facilities are kept clean and safe for passengers (TfL 2001, MTC 2006). Collectively, these service features can improve the quality of transit.

It is important to note that there are multiple forms of coordination that require different levels of operator and/or government involvement and depend on the level and nature of transit demand in each urban area. Physical coordination, the most common and least expensive form of coordination, involves establishing points of transfer between and among transit networks (Henry 1990). In addition, information coordination is essential to the distribution of up-to-date route, fare, and timetable data, while institutional coordination ensures public sector participation in the ongoing planning of interoperator schemes.

Under optimal conditions, the more integrated the transit system, the greater the potential for passengers to reap significant cost and time-savings (Nash 1988). For example, interoperator coordination can establish the conditions for two or more operators to develop a discounted, multi-ride ticket/pass. However, political, operational, organizational, and financial barriers often pose challenges to coordinating transit services across jurisdictions within a region. In addition, the specific institutional structure of an urban area can limit coordination (Jemelin and Kaufman 2001; Lee and Rivasplata 2001). For example, in a number of cities with privately- 
operated systems (e.g., Britain in the 1990s, Chile in the 1980s), local government has played a very minor role in the planning and regulation of transit systems, leaving it to the operators. In Britain, the Conservative government even discouraged interoperator transit coordination through anti-competitive legislation (OFT 1999; Dodgson 2000; White 2002).

Given the importance of government in the planning and coordination of transit, many argue that a condition necessary for the development of a well-integrated transit system is that an autonomous authority be charged with establishing a set of through-service standards (Nash 1988; Tyson 1990). Based on past experience, when establishing a set of intermodal transport objectives, it is essential that this authority balance the commercial interests of the operators with the needs of passengers (NEA 2003; Rivasplata 2006). It is important that regional coordination policy be transparent to all and designed to preserve operator integrity and competitiveness and respond to a proven demand for transfers.

Despite its importance, relatively little research has been conducted in the U.S. on specific methods and criteria for measuring and evaluating regional coordination and integration using concrete indices and indicators. In contrast, while many studies on the subject tend to define regional coordination broadly, they normally do not offer any specific indicators with which to measure it.

The study of transit integration has provided a number of perspectives from which to evaluate integration. A European Commission study conducted by NEA Transport Research and Training cited a set of theoretical perspectives for approaching coordination (NEA 2003):

1. The engineer's vision of a well-planned system that promotes a solution but does not account for its eventual impacts.

2. The public management perspective that considers the behavior of public and private entities but often exerts only limited control over service provision.

3. A vision focused on institutions and their evolution that explains influence but does not offer an optimal design.

4. The microeconomics perspective that analyzes certain aspects of coordination (e.g., market failure) but pays little attention to implementation.

This nationwide survey on transit coordination took the second option, largely approaching transit service from a public management perspective. That is to say, in metropolitan regions where multiple transit agencies operate, the survey polled agencies on their perspectives concerning coordination as well as their common 
practices and relationships with other transit agencies. We have sought to explore various aspects of transit coordination in transit systems of varying size and geographic location. While some coordinative efforts are well-documented in larger metropolitan regions, such as the San Francisco Bay Area (MTC 2006, Miller et al. 2005), this survey provided information on the magnitude and nature of coordinative efforts throughout the country. The following section describes the scope of the survey, the methodology employed, and descriptive statistics and an analysis of the data.

\section{Nationwide Survey of Transit Agencies}

The survey was conducted over a two-month period, from April to June 2010. The 2008 National Transit Database (NTD), administered by the Federal Transit Administration, provided a list of 590 transit agencies, all of which provided at least one fixed-route transportation mode. All of these agencies were invited to participate in the survey through email or letter. The invitation explained the purpose of the survey, emphasizing that participation in the survey was voluntary. Respondents to the survey were directed to a computer link from which they could fill out a web-based survey on www.surveymonkey.com. The site provided an overview of the project, the purpose of the survey, survey instructions, and a statement assuring confidentiality.

The survey consisted of two parts. The first part included questions related to agency profile, operating geographic area, and contracting characteristics, such as the number of contractors employed and the functions contracted out. The second part featured questions related to regional coordination. ${ }^{1}$ Questions focused on the five following categories of regional coordination:

1. Fare coordination-the coordination of ticketing arrangements and fare structures.

2. Service schedule coordination-the coordination of vehicle schedules to facilitate transfers.

3. Information coordination - the joint distribution of service information by transit operators.

4. Facilities/vehicle-including the collective purchase of equipment, vehicle, and other resources on the part of transit agencies, for the purposes of achieving economies of scale.

5. Joint agreements-formal contracts between agencies for the provision of specific transit services. 
A total of 202 responses were received, with an overall response rate of 34 percent, a good result for an agency survey of this nature. The sample represents differentsize agencies from 45 states and all major regions of the United States. As Table 1 shows, the survey captured agencies that were closely representative of the fleet sizes of the population of fixed-route transit agencies provided by the NTD. The sample population, however, captured a significantly smaller percentage of agencies with fewer than 25 vehicles and a larger percentage of agencies with 100-249 vehicles.

\section{Table 1. Fleet Sizes of Agencies Surveyed and Entire Population}

\begin{tabular}{ccc}
\hline $\begin{array}{c}\text { Vehicles Operated at } \\
\text { Maximum Service } \\
\text { (Total Fleet Size) }\end{array}$ & Survey Sample & $\begin{array}{c}\text { Entire Population of } \\
\text { Fixed-Route Agencies }\end{array}$ \\
\hline Under 25 & $28 \%$ & $43 \%$ \\
$25-49$ & $23 \%$ & $19 \%$ \\
$50-99$ & $14 \%$ & $16 \%$ \\
$100-249$ & $19 \%$ & $11 \%$ \\
$250-499$ & $7 \%$ & $6 \%$ \\
$500-999$ & $4 \%$ & $3 \%$ \\
$1,000+$ & $5 \%$ & $3 \%$ \\
\hline
\end{tabular}

Depending on the presence of other fixed-route transit agencies in the region, respondents were asked a different set of questions. Of the surveys received, 91 respondents (45\%) indicated that their agency is the only fixed-route transit agency operating in their region, and thus, were not included in the analysis of multioperator markets. The remaining 111 respondents reported working for agencies in regions with two or more fixed-route transit agencies and were asked additional questions related to several aspects of regional coordination. Before conducting the statistical analysis, we checked and confirmed that the survey respondents did not overwhelmingly represent multiple transit agencies from the same urban area, i.e., which could have provided duplicate responses. ${ }^{2}$

\section{Survey Data Analysis}

\section{Descriptive Statistics}

\section{Fare Coordination}

Agencies were polled on a number of questions related to fare coordination (Table 2). Of 111 responses, more than half indicated that their region has a coordinated 
fare system. More than half of the agencies sell transit tickets, passes, or tokens that can be used on other transit systems, and a similar number sell tickets through other systems in the region.

\section{Table 2. Questions Related to Fare Coordination}

\begin{tabular}{|c|c|c|c|c|c|}
\hline & \multicolumn{2}{|c|}{ Yes } & \multicolumn{2}{|c|}{ No } & \multirow{2}{*}{$\frac{\text { Total }}{N}$} \\
\hline & $N$ & $\%$ & $N$ & $\%$ & \\
\hline $\begin{array}{l}\text { Has a coordinated regional fare system (e.g., the charging of a } \\
\text { transfer fare) been established in your region? }\end{array}$ & 58 & 52 & 53 & 48 & 111 \\
\hline $\begin{array}{l}\text { Does your agency sell transit passes, tickets, or tokens that can be } \\
\text { used on other transit systems? }\end{array}$ & 60 & 54 & 51 & 46 & 111 \\
\hline $\begin{array}{l}\text { Do other transit agencies in your region offer or sell transit passes, } \\
\text { tickets, tokens that can be used on your system? }\end{array}$ & 60 & 55 & 50 & 45 & 110 \\
\hline $\begin{array}{l}\text { Does your agency allow transfers from other transit systems for free } \\
\text { or with a discounted fare? }\end{array}$ & 70 & 63 & 41 & 37 & 111 \\
\hline
\end{tabular}

$N=$ number of respondents

While about half of the 111 respondents indicated that a coordinated fare system has been established in their region, the data suggest that the other half operate in regions that do not have a coordinated fare system. Coordinated fare systems generally are considered beneficial to customers, but agencies may have a difficult time implementing a coordinated fare system for a number of reasons, including institutional, financial, or technological hurdles (Miller et al. 2005; Yoh, Iseki, and Taylor 2008). While these difficulties may prevent agencies from providing their customers with a coordinated fare system, agencies may allow customers to transfer for free or with a discount. A discounted or free fare may encourage ridership among riders who use more than one transit system by bringing the entire trip cost down (although reduction in fare revenue could be a financial problem for transit agencies). Among the 68 agencies that allow discounted or free transfers, 49 indicated that their agency allows transfers from other transit systems in the region without an additional fare and 19 reported that their agency allows transfers for an additional fare.

Of the 60 transit agencies that sell fare media for use on other transit systems or whose fare media are sold by other systems, the most popular was a paper pass valid for one week or longer, followed by a one-ride ticket or token. The one-week pass was used by more than half of the responding agencies. These media are inexpensive to implement compared to a smart card system or magnetic swipe card, 
which may require installation of new equipment and other ongoing expenses, as well as identification and account information from customers (Giuliano, Moore, and Golob 2000; Yoh et al. 2006). These cost factors may account for the popularity of paper passes as opposed to smart cards and magnetic swipe cards, which only 25 and 12 percent of respondents used, respectively. Many transit agencies are concerned about uncertainty regarding the costs associated with implementing a technologically-sophisticated fare collection system such as a smart card system relative to its potential benefits (Yoh et al. 2006; Iseki, Yoh, and Taylor 2007). Paper passes that are shared among agencies, on the other hand, provide a low-cost way of coordinating fares.

\section{Service Schedule}

Agencies were polled on two questions related to service schedule (Table 3). Of the 111 responses, close to 70 percent of these agencies coordinate both their daily and weekly service schedules and timetables with other agencies in their region. While service schedule and time schedule coordination are a very basic level of coordination, they can be very beneficial to transit passengers by reducing passenger wait time, particularly because travelers commonly perceive out-of-vehicle (walking, waiting, and transferring) time more onerous than in-vehicle time (Wardman 2001; Iseki and Taylor 2009). In addition, this type of coordination also may produce benefits to transit operators, as ridership has been shown to increase and customer complaints decrease. A number of other benefits can take place when transit systems are able to coordinate schedules for the convenience of their passengers (Miller et al. 2005).

Table 3. Questions Related to Service Schedule

\begin{tabular}{llllll}
\hline & \multicolumn{2}{c}{ Yes } & & No & Total \\
\cline { 2 - 6 } & $N$ & $\%$ & $N$ & $\%$ & $N$ \\
\hline $\begin{array}{l}\text { Does your agency take into account the service schedule of other } \\
\text { transit agencies in the region to determine the daily and weekly } \\
\text { service schedules of your agency? }\end{array}$ & 78 & 70 & 33 & 30 & 111 \\
$\begin{array}{l}\text { Does your agency determine time schedules of buses, streetcars, } \\
\text { or other fixed-route transit services in coordination with the } \\
\text { schedules of other transit systems, taking into account transfer } \\
\text { time for users at major transfer points? }\end{array}$ & 76 & 68 & 35 & 32 & 111 \\
\hline
\end{tabular}




\section{Information}

The survey asked several questions concerning the joint provision of information. Of the 111 respondents, 83 (75\%) provide information jointly with other transit agencies. The most common information provided was route maps and time schedules, which 67 percent of these agencies provided. The provision of integrated information can make it easier for customers to use transit to travel across areas served by multiple agencies (Miller et al. 2005).

The 83 agencies providing joint information indicated the use of a variety of media (Table 4). The most commonly-used media were information pamphlets $(65 \%$ of the agencies), while less than half of agencies shared websites. A few agencies noted that while they do not share websites, they do provide links to the websites of other agencies. Regional websites, such as 511.org in the San Francisco Bay Area or tripplanner.mta.info in the New York City area, can be very helpful for planning routes across more than one transit system or finding transit information easily and quickly. Nevertheless, information pamphlets may be more popular, as they are accessible to everyone, including transit dependents that are important customers but are less likely to have access to the Internet (e.g., for economic reasons).

\section{Table 4. Media Used in Joint Provision of Information}

\begin{tabular}{lll}
\hline & N & $\%$ \\
\hline Information pamphlets & 54 & 65 \\
Telephone service numbers & 49 & 59 \\
Transfer centers that provide information & 44 & 53 \\
Shared websites & 37 & 45 \\
On-board display & 14 & 17 \\
Other & 15 & 18 \\
\hline
\end{tabular}

Total number of respondents: 83

Note: Respondents provided multiple answers.

The survey findings indicated that most agencies make use of real-time information. In addition to schedule coordination, the provision of real-time vehicle arrival information has proved effective in reducing waiting time and improving the transit passenger experience (Dzieken and Kottenhoff 2007; Mishalani and McCord 2006). Most of the 111 agencies indicated that they use real-time information such as automatic vehicle location systems, while only about one-third indicated that they do not use it. However, there is little coordination in the use of real-time information among transit agencies. Most agencies use real-time information within their own organization but do not share with other agencies. 


\section{Facilities and Signage}

Finally, agencies were polled on facility sharing and signage design (Table 5). Approximately 69 percent of the 111 agencies polled shared facilities (e.g., terminals, shelters) with other agencies, although some facilities required more coordination than others. Among agencies that share transfer points and/or facilities, 74 percent indicated that these points are clearly designated, facilitating better operational coordination between agencies and convenient transfers for passengers. Comprehensive planning for and establishment of transfer points can collectively be undertaken by most of the agencies.

Table 5. Questions Related to Facilities and Signage

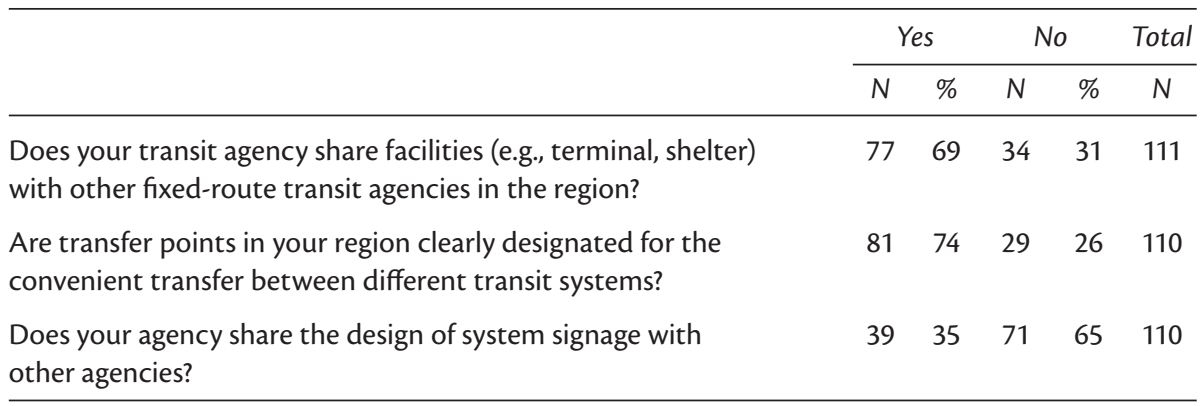

$N=$ number of respondents

The sharing of signage design was not a very common practice. Of those agencies polled, only 35 percent share with other agencies. While shared signage design may not be an essential component of regional coordination, consistency in their use can enhance customer comprehension of information across transit systems and improve their perception that transit agencies are working within a unified transit system (rather than a disjointed system).

Agencies were questioned about the types of facilities shared. Shelters were shared most often between agencies, while 62 percent of agencies shared a terminal with other agencies. Shared facilities for passengers, such as well-designed bus stops or terminals, can reduce walking distance between systems, facilitating transfers for passengers (Parsons Brinckerhoff 2002; Iseki and Taylor 2009). Agencies may have problems with sharing facilities when they cannot reach agreements on maintenance or other responsibilities. While it may be easy to reach interoperator agreements on bus shelters, facility maintenance agreements are more difficult to reach, as evidenced by the fact that only nine percent of agencies polled had such arrangements. 


\section{Joint Agreements and Discount Programs}

Several questions were asked regarding existing agreements between agencies. A large number of respondents indicated that their agencies currently have agreements with other agencies to expand routes (Table 6). The coordinated expansion of routes can help link locations that do not have service and help prevent the duplication of routes by coordinating service.

Table 6. Existing Agreements between Agencies

\begin{tabular}{lcc}
\hline & $N$ & $\%$ \\
\hline To expand routes & 34 & 38 \\
To introduce a regional transit smart card that can be used on multiple systems & 26 & 29 \\
To jointly market transit services & 24 & 27 \\
To jointly share data on ridership, accidents, etc. & 16 & 18 \\
To increase service frequency & 15 & 17 \\
To jointly train transit workers or share the same training materials & 8 & 9 \\
Other & 47 & 52 \\
\hline
\end{tabular}

Total Number of respondents: 90

Note: Respondents provided multiple answers.

Respondents acknowledged the existence of several types of discount programs. While these programs may not be directly related to regional coordination, they often help agencies increase ridership (Pucher and Kurth 1989). More than half of the respondents indicated that their agencies have a discount program. Collegebased discounts were the most popular, perhaps because many students do not own a car.

\section{Respondent Comments}

In addition to the multiple-choice section of the questionnaire, survey respondents-major stakeholders in the planning process-were asked to provide open-ended comments regarding regional coordination. Experience abroad has shown that stakeholder commitment is important in the improvement of transit coordination. Respondents commented on a variety of issues related to regional coordination, noting the difficulties in implementing regional coordination and also highlighting some of their successes.

Respondents commented on challenges associated with implementing regional coordination, including political barriers such as home rule; institutional barriers, such as a lack of a strong coordinating MPO or RTA; and financial hurdles, such as a lack of funding for regional services. As noted by some of the comments from transit agency executives, agencies face challenges in coordinating transit systems 
where longstanding political, institutional, or financial issues persist. Finding ways around these obstacles is likely to be a key step in advancing a region's level of coordination.

One respondent referred to some of the difficulties of coordinating with other agencies, stating that it is "not the practicalities that create the challenge," but rather "the political and personal realities." Where home rule is well established and counties are fiscally responsible for providing transit service, many agencies are unwilling to cooperate (e.g., coordinate timetables) if they do not have to, and it often is difficult to force them to cooperate. Another respondent similarly commented on the difficulties that small agencies have working with larger or more powerful agencies. The respondent noted that smaller agencies often lack the political power to initiate coordination, although they make efforts to do so.

Other respondents pointed to the complexity in achieving coordination efforts when working with other agencies, identifying the difficulty in getting all players to the table to reach an agreement. They pointed out that in order for multiple transit agencies to coordinate effectively, there needs to be strong regional governance, as well as a focus on collective achievements (e.g., incentives for agencies to switch from individual agency fare collection to a regional revenue sharing scheme, based on smart card technology).

In addition, the survey revealed that transit coordination is hampered by local funding requirements. A respondent remarked that when operating funds are secured through countywide sales tax levies, it is difficult for transit agencies to cross county borders to service other counties, even when there are destination points within those counties. ${ }^{3}$ The respondent suggested that one way to alleviate the situation might be for federal or state governments to provide additional operating funding.

Several other respondents commented on the success of coordination in their regions, noting the benefits that passengers receive from a coordinated, regional transit system, such as reduced travel costs. Other respondents remarked that at the regional or state level, it is beneficial to promote legislation creating regional transit authorities. These responses indicate that many transit directors believe that regional coordination can benefit the user, but that interagency working relationships require regional governance, regional funding mechanisms, and legislative initiatives that promote regional coordination. 
Many transit agencies in the sample operated in regions with one or two other fixed-route agencies. Respondents from small- and mid-size metropolitan regions often reported lower levels of regional coordination, suggesting that as regions grow, many of the agencies in these regions: (1) respond to the increasing demand for regional transit, and/or (2) encounter opportunities to coordinate with other transit agencies. As a result, close working relationships often are established. In this sense, early cooperation between agencies can lay the foundation for successful transit coordination as a region expands.

\section{Analysis of Potential Factors Related to Regional Coordination}

Some questions on the survey were designed to test hypotheses based on factors that appeared to be related to regional coordination. Two of the questions, hypotheses, and test results are described below. It should be noted that results are reported for the first and second tests without multiple agencies from the same urban area.

1. Is regional population size correlated with level of coordination? It was hypothesized that population size may be correlated with regional coordination because more populous regions tend to have more transit agencies and greater demand for regional transit service and integration. A t-test was run for independent samples on all measures of coordination, testing the mean population size of urbanized areas grouped by their responses to 12 measures of coordination. No significant difference was found in population size between responses for measures of regional coordination in the survey at the $95 \%$ confidence level. ${ }^{4}$

2. Is the number of transit agencies in a region correlated with level of coordination? It was hypothesized that regions with more transit agencies have more opportunities to coordinate with other agencies, improving the chances for these agencies to establish coordinating relationships. In order to test this hypothesis, these agencies were arranged into the three groups, based on the reported number of other transit operators in the region: one to two agencies; three to five agencies, and more than five. ${ }^{5}$ The responses were tabulated, and Pearson's Chi-square tests grouped by responses of "yes" or "no" for all measures of coordination were run. It was found that agencies reporting the existence of 3 or more other transit agencies had higher levels of coordination for 7 of the 12 measures of coordination that we examined at the $95 \%$ confidence level. $^{6}$ 


\section{Conclusion}

While largely descriptive in nature, the survey results provide some important insights into the activities of transit agencies and the settings within which they are expected to coordinate with other providers. The survey results suggest that regions with four or more transit agencies are likely to have more transit coordination than regions with fewer than four agencies. Perhaps the larger the region, the greater the number of transit agencies there are and the greater the need, demand, and expectation to introduce at least a minimum level of coordination, i.e., most large regions have some form of coordination that allows for transfer (interchange) between transit systems and modes?

In addition, these results could suggest that if there are only two transit agencies in a region (e.g., one based in the economically-declining inner city and the other in a relatively wealthy suburb), conflicts over such issues as funding may prevent operators from working together. In contrast, if there are four or more operators in a region, there may be less in-fighting among agencies. One of the operators may act as a facilitator and mediator of conflicts, e.g., placing greater focus on regional issues and connections.

While a large number of agencies reported high levels of cooperation, regional coordination is still lacking in many areas of the U.S. Barriers to regional coordination often are political, institutional, or financial in nature, and regional entities lack the ability to integrate transit services due to political and administrative difficulties in coordinating public agencies (e.g., no control of transit agencies within their region or require that standards are met). In some areas, the regional transportation planning organization plays only a limited role in the ongoing planning of transit services in a metropolitan region, many times as the result of political factors. In other cases, the regional government may have very limited resources that can be used to promote coordination. Except for a few cases, dedicated resources for coordination are practically non-existent in many regions-often, MPOs lack either the political power or will to generate funding for ongoing interagency coordination. In addition, there are cases in which inherent conflicts exist between the benefits of regional coordination and the costs to individual transit agencies. For example, while transit users may benefit from regional coordination, for taxpayers in some jurisdictions of the region, the costs may outweigh the benefits.

Overcoming these hurdles and building relationships are important steps to establishing better regional coordination. We argue that for widespread transit coordination to be achieved, it is essential that regional transportation plans propose 
policies and financial support for ongoing coordination. In addition, transit service plans can incorporate or balance the needs and desires of all parties-including passengers, operators, communities, and society at large - through a comprehensive planning and outreach process that encourages input from all of these groups and that works through the issues to reach consensus. From an equity point of view, it is important to conduct a careful analysis of costs and benefits for each of these parties as well as society as a whole, not only taking into account direct economic costs and benefits but also indirect social and environmental ones. Once the net benefit of regional coordination is confirmed and adequate compensation for losses is given, this comprehensive planning process will gain greater public acceptance. Clearly, the cost of adopting and implementing specific integration strategies will need to be carefully considered and discussed among all parties involved.

One of the principal strategies warranting consideration in many cities is the granting of greater power to metropolitan planning organizations (MPOs) to promote regional transit policies and generate funding opportunities for the implementation of interagency initiatives. We argue in favor of greater dialogue among transit agencies, contractors, regulators, and planning bodies. There are examples of successful coordination in the U.S., such as in the Washington, D.C. area and in the San Francisco Bay Area, where regional transit agencies and the local MPO regularly meet to discuss issues of regional importance.

In the case of the San Francisco Bay Area, the Metropolitan Transportation Commission (MTC) has played an important role in the planning and funding of mutually agreed-upon programs (e.g., Clipper smartcard, 511 information services). It has facilitated the ongoing coordination of services, often tying available funding to operator participation. In addition, the MTC has begun to work closely with its regional planning counterparts to coordinate transportation with land use, housing, water resources, and air quality.

From the user perspective, as economic and social activities extend across a region, there is a need for seamless regional transit service. A lack of coordination not only places a significant burden on those transit users who have to travel on multiple transit systems, but also reduces the chance of attracting more riders, reducing congestion, and lowering vehicle emission and greenhouse gas levels. Transit agencies and regional transportation agencies need to take a holistic approach to incorporating regional transit coordination in their provision and planning, particularly in response to the need of transit dependents and the threats of environmental degradation associated with widespread automobile dependence. Addressing 
these issues is central to promoting livable communities and a sustainable environment. Further research is warranted to measure the net benefits of regional coordination of transit service, to explore successful coordination strategies, and to identify ways of adapting them to local circumstances and conditions.

\section{Endnotes}

${ }^{1} \mathrm{~A}$ complete list of the survey questions is available upon request.

${ }^{2}$ The 111 agencies with at least one other fixed-route transit agency in the same region came from 81 different urban areas. Los Angeles-Long Beach-Santa Ana had 7 agencies, the highest in the survey. Other multi-agency urban areas included NY-Newark, NY, NJ, CT, with four agencies; Chicago, Atlanta, Phoenix-Mesa, Riverside-San Bernardino, and San Francisco-Oakland, with 3; and several others with 2.

${ }^{3}$ This is also what was found in the case of one transit agency in the Greater New Orleans Region in the larger research. The transit director stated that the transit agency needs to be very careful about the use of local property tax revenue that funds local transit service, and that it cannot get into extensive regional coordination without making sure that it will benefit the taxpayers within its service area.

${ }^{4}$ Values for t-test are available upon request.

${ }^{5}$ It should be noted that when referring to the number of transit agencies operating in a region, the agency being surveyed should be added. As such, these 3 groupings correspond to 2-3 agencies, 4-6 agencies, and more than 7 agencies in a single region.

${ }^{6}$ Agencies that reported having 3 or more other transit agencies operating in their region had significantly higher levels of transit coordination (than agencies with 1-2 other operators) in the following areas: (a) coordinated fares, (b) interchangeable transit passes, (c) free or discounted transfers, (d) coordinated daily and weekly service schedules, (e) coordinated timetables, (f) joint provision of information, and (g) existing interagency agreements. Values for chi-square tests are available upon request.

${ }^{7}$ Survey results indicated that some agencies were particularly well-coordinated. While most respondents requested that their agency name not be disclosed, those that allowed this information to be released reported high levels of coordination. For instance, the San Diego Metropolitan Transit System (CA) and Intercity 
Transit (Olympia, WA) reported high levels of fare coordination, while CityBus (Santa Rosa, CA) and StarMetro (Tallahassee, FL) reported having coordinated service schedules. Similarly, Thousand Oaks Transit (CA) and Glendale Transit (AZ) reported high levels of information coordination, while Petaluma Transit (CA) and Metropolitan Atlanta Rapid Transit Authority (GA) reported high levels of facility coordination. Finally, in the area of joint agreements, Bay Metropolitan Transit (Bay City, MI) and Washington City Transit (PA) reported having several joint agreements with other agencies (e.g., to increase service frequencies, expand routes, jointly market services).

\section{Acknowledgments}

The research conducted for this paper was supported by grants from the Mineta Transportation Institute at San Jose State University and the University Transportation Center of the University of New Orleans. This work came from a larger effort conducted by a research team of faculty and students at the University of New Orleans and San Jose State University. We thank the transit officials who participated in the survey and paper reviewers for their comments on the earlier versions of this paper. The views presented are the sole responsibility of the authors and not those of the funding agencies.

\section{References}

Chisholm, D. Coordination Without Hierarchy. 1989. Berkeley: University of California Press.

Cook, T. J., J. J. Lawrie, and A. J. Henry. 2003. From rural single-county to multicounty regional transit systems: benefits of consolidation. Transportation Research Record 1841: 54-61.

Dodgson, J. 2000. Effective competition in the bus industry. In Integrated Transport Policy, J. Preston, H. Smith, and D. Starkey, eds. Aldershot (U.K.): Ashgate.

Dziekan, K. and K. Kottenhoff. 2007. Dynamic at-stop real-time information displays for public transport: Effects on customers. Transportation Research Part A: Policy and Practice 41: 489-501.

Giuliano, G., J. E. Moore, II, and J. Golob. 2000. Integrated smart card fare system: results from field operational test. Transportation Research Record 1735: 138146. 
Henry, E. 1990. The metro put to the test in Latin America. In Rail Mass Transit for Developing Countries. London: Thomas Telford, Ltd.

Hensher, D., and A. Brewer. 2001. Transport: An Economics and Management Perspective. New York: Oxford University Press.

Iseki, H., C. Rivasplata, R. Houtman, A. Smith, C. Seifert, and T. Sudar. 2011. Examination of regional transit service under contracting: $A$ case study in the greater New Orleans Region. Report No. CA-MTI-11-2904. Jointly published by Mineta Transportation Institute and Gulf Coast Research Center for Evacuation and Transportation Resiliency.

Iseki, H., A. C. Yoh, and B. D. Taylor. 2007. Are smart cards the smart way to go? Examining the adoption of smart card fare systems among U.S. transit agencies. Journal of the Transportation Research Board 1992: 45-53.

Iseki, H., and B. D. Taylor. 2009. Not all transfers are created equal: Toward a theoretical framework relating transfer connectivity to travel behavior. Transport Reviews 29(6): 777-800.

Lee, R., and C. Rivasplata. 2001. Metropolitan transportation planning in the 1990s: Comparisons and contrasts in New Zealand, Chile and California. Transport Policy 8(1): 47-61.

London Transport Planning (LTP). 1997. Interchange in London: Patterns of access interchange at rail stations outside central London.

Metropolitan Transportation Commission (MTC). 2006. Transit connectivity plan.

Meyer, M. D., S. Campbell, D. Leach, and M. Coogan. 2005. Collaboration: The key to success in transportation. Transportation Research Record 1924: 153-162

Miller, M. A., L. Englisher, B. Kaplan, and R. Halvorsen. 2005. Transit service integration practice. Transportation Research Record 1927: 101-111.

Mishalani, R., and M. McCord. 2006. Passenger wait time perceptions at bus stops: Empirical results and impact on evaluating real-time bus arrival information. Journal of Public Transportation 9(2): 89-106.

Nash, C. 1988. Integration of public transport: An economic assessment. In Bus Deregulation and Privatisation. Aldershot: Avebury. 
NEA Transport Research and Training, OGM, Oxford University, Erasmus University, TIS.PT and ISIS. 2003. Integration and regulatory structures in public transport, Final report to DG TREN. Rijswijk, The Netherlands: NEA.

Parsons Brinckerhoff. 2002. Intermodal facilities. In PB Network: 60.

Pucher, J., and S. Kurth. 1989. Verkehrsverbund: The success of regional public transport in Germany, Austria and Switzerland. Transport Policy 2(4): 279-291.

Rivasplata, C. 2000. Alternatives for promoting public transport integration in the Americas. In Urban Transportation and the Environment, O. Diaz, G. Palomas and C. Jamet, eds. Rotterdam (The Netherlands): Balkema.

Rivasplata, C. 2006. An Analysis of the impacts of British reforms on transit integration in the metropolitan areas. Ph.D. Dissertation, University of California, Davis.

Stokes, G. 1994. The role of public transport interchange in improving public transport. Paper presented at the 22nd Annual PTRC Conference, Seminar E: 235-236.

Transport for London (TfL). 2001. Intermodal Transport Interchange for London: Best Practice Guidelines.

Tyson, W. 1990. Effects of deregulation on service co-ordination in the metropolitan areas. Journal of Transport Economics and Policy 24(3): 283-293.

United Kingdom. Office of Fair Trading (OFT). 1999. The Competition Act 1998: The Major Provisions. London: HMSO.

Wardman, M. 2001. A review of British evidence on time and service quality valuations. Transportation Research, Part E, Logistics and Transportation Review 37E 2-3: 107-128.

White, P. 2002. Public Transport: Its Planning, Management and Operation. London: Spon Press.

Yoh, A. C., H. Iseki, B. D. Taylor, and D. King. 2006. Inter-operator smart card systems: Are we moving too slow or too fast? Journal of the Transportation Research Board, 1986: 69-77.

Yoh, A. C., H. Iseki and B. D. Taylor. 2008. Smart cards, slow deployment: Findings from interviews with U.S. transit agencies. California PATH Research Report, 
UCB-ITS-PWP-2008-1, California PATH Program, Institute of Transportation Studies, University of California, Berkeley.

\section{About the Authors}

Charles R. Rivasplata (charles.rivasplata@sfmta.com) is an Adjunct Lecturer in the Urban and Regional Planning Department at San Jose State University, where he teaches courses on transportation planning. He is also a Senior Planner at the San Francisco Municipal Transportation Agency (SFMTA). He completed master's degrees in Civil Engineering and in City Planning at the University of California, Berkeley (1991) and a Ph.D. at the University of California, Davis (2006). His doctoral dissertation focused on the impacts of Labour Party reforms on transit integration in the U.K. His research interests include transit privatization and deregulation, regional governance, travel demand management (TDM), and transit coordination. He has taught classes on transport planning at the University of California, transportation policy at Cambridge University, and TDM at the Central University of Venezuela.

HIROYUKI ISEKI (hiseki@umd.edu) is an Assistant Professor of Urban Studies and Planning and a research faculty member at the National Center for Smart Growth at the University of Maryland, College Park. His current research focuses on balancing efficiency, effectiveness, and equity in public policy and planning with special attention to transportation, environment, and land use. His research interest includes transportation economics and finance, public transit planning and management, travel behavior analysis and modeling, regional transportation planning, and geographic information systems (GIS) applications to research and practice in public policy and planning. His work has been published in a range of transportation and planning journals, including Transportation Research A: Policy and Practice, Transport Reviews, Journal of the Transportation Research Board, Journal of Public Transportation, and Journal of Planning Education and Research.

AdAM L. SMIтH (adamleesmith@gmail.com) is a graduate student in the Urban and Regional Planning Department at San Jose State University. His professional interests include transportation and land use planning, transportation finance, urban design, and GIS applications for urban and regional planning. 